\title{
Signatures of Random and Selective Mass Extinctions in Phylogenetic Tree Balance
}

\author{
STEPHEN B. HEARD ${ }^{1}$ AND ARne Ø. MOOERS $^{2}$ \\ ${ }^{1}$ Department of Biology, University of New Brunswick, Fredericton, New Brunswick E3B 6E1, Canada; \\ E-mail: sheard@unb.ca \\ ${ }^{2}$ Department of Biological Sciences, Simon Fraser University, Burnaby, British Columbia V5A 1S6, Canada; \\ E-mail: amooers@sfu.ca
}

\begin{abstract}
Current models of diversification with evolving speciation rates have trouble mimicking the extreme imbalance seen in estimated phylogenies. However, these models have not incorporated extinction. Here, we report on a simple simulation model that includes heritable and evolving speciation rates coupled with mass extinctions, Random (but not selective) mass extinctions, coupled with evolving among-lineage variation in speciation rates, increase imbalance of postrecovery clades. Thus, random mass extinctions are plausible contributors to the imbalance of modern clades. Paleontological evidence suggests that mass extinctions are often random with respect to ecological and morphological traits, consistent with our simulations. In contrast, evidence that the current anthropogenic mass extinction is phylogenetically selective suggests that the current extinction episode may be qualitatively different from past ones in the way it reshapes future biotas. [Biodiversity; mass extinction; phylogeny; speciation; tree balance.]
\end{abstract}

Phylogenetic tree shapes are governed by relative rates of speciation and extinction (Mooers and Heard, 1997). We have both elegant theory (e.g., Yule, 1924; Nee et al., 1995) and data (e.g., Willis, 1922; Purvis and Agapow, 2002) concerning tree shapes, especially imbalance (the extent to which lineages within a clade tend to differ in diversity). A simple null model for imbalance is the equal rates Markov (ERM) model, under which instantaneous rates of diversification (speciation minus extinction) are equal for all lineages within an evolving clade, but stochastic variation in realized diversification rates can produce a variety of actual tree shapes (Mooers and Heard, 1997). The consequences of the ERM model for patterns in diversity are well known, but the consensus from modern compilations is that in real clades lineages differ in diversity much more than expected under the ERM model (reviewed by Purvis, 1996; Mooers and Heard, 1997; see also Harcourt-Brown et al., 2001; Stam, 2002; Purvis and Agapow, 2002). This consensus suggests strongly that real diversification rates are not equal, with some groups significantly more diverse than others, and much effort has been spent identifying causes for high (and low) diversity in particular clades (e.g., Heard and Hauser, 1995; Gittleman and Purvis, 1998; Barraclough and Savolainen, 2001; Lieberman, 2001).

Importantly, however, the degree of departure of real trees from the ERM model is itself surprising; i.e., simple but plausible models of macroevolution often predict phylogenies more imbalanced than those predicted by the ERM model but not as strongly imbalanced as real phylogenies. The motivation for the present study was a simple model presented by Heard (1996) highlighting this discrepancy. In this model, speciation rate depended on an evolving trait of individuals (such as body size). However, parameter values best mimicking observed tree shapes corresponded to implausibly rapid trait evolution and, therefore, implausibly broad variation in speciation rates. For instance, the best match to observed tree shapes had $>30 \%$ of sister pairs differing by at least a factor of two in trait value (and hence in their subsequent probability of speciation). Such differences seem extreme compared with trait distributions in real clades, even those representing adaptive radiations. For instance, among Darwin's finches (Geospiza, Cactospiza, and Camarhynchus), three ecologically important traits (body mass, beak depth, and beak length) never vary twofold between sister species and rarely differ so much even among nonsister congeners $(11 \%, 5 \%$, and $16 \%$ of 19 congeneric pairs, respectively; our analysis of data from Lack [1947] and Grant [1986]). Kirkpatrick and Slatkin (1993) reached a similar conclusion based on a very different model of diversification, and more sophisticated models (Losos and Adler, 1995; Chan and Moore, 1999) only increase our surprise, 
because they draw attention to biological mechanisms that can reduce (not increase) imbalance.

Both Heard's (1996) and Kirkpatrick and Slatkin's (1993) models considered only the speciation component of diversification. Here, we explore how simple models of mass extinction interact with heritable speciation rates to alter phylogenetic tree shape. The simplest form of mass extinction (random extinction of lineages with respect to their speciation probabilities) is also the most powerful generator of realistic (i.e., imbalanced) tree shapes. We also review paleontological evidence that past mass extinctions have most likely included important elements of randomness, and we suggest that episodes of random mass extinction may have contributed (in addition to heritability of speciation rates and perhaps other mechanisms) to the strongly imbalanced phylogenetic tree shapes we see in nature-tree shapes that reflect dramatic skewness in the sizes of modern clades.

\section{METHODS}

We simulated radiation, extinction, and recovery in hypothetical clades using a computer program (available on request from
S.B.H.) written in Microsoft QuickBASIC 4.5. The history of each simulated clade included three phases. First, the clade radiated from a single ancestor to reach a target size (number of descendent species) $N$. Second, the clade experienced a single episode of mass extinction (either random or selective) that reduced its size to $N^{\prime}$. Third, diversification resumed until the clade regained the target size $N$. We refer to the clades at the end of each phase as pre-extinction, postextinction, and postrecovery clades, respectively (Fig. 1). We also considered properties of the midradiation clade, which is the clade at size $N^{\prime}$ during its original radiation (Fig. 1).

\section{Phase I: Initial Radiation}

Following Heard (1996), our model allowed for variation in speciation rates among lineages and through time. At any time during radiation, each extant species had an associated speciation probability that depended on the value of a quantitative trait of individuals evolving in a random walk. We began with a single species and then stepped through time allowing both trait evolution and speciation (but not extinction) until the target clade size $N$ was reached. We grew trees of size $N=40$ species (results for

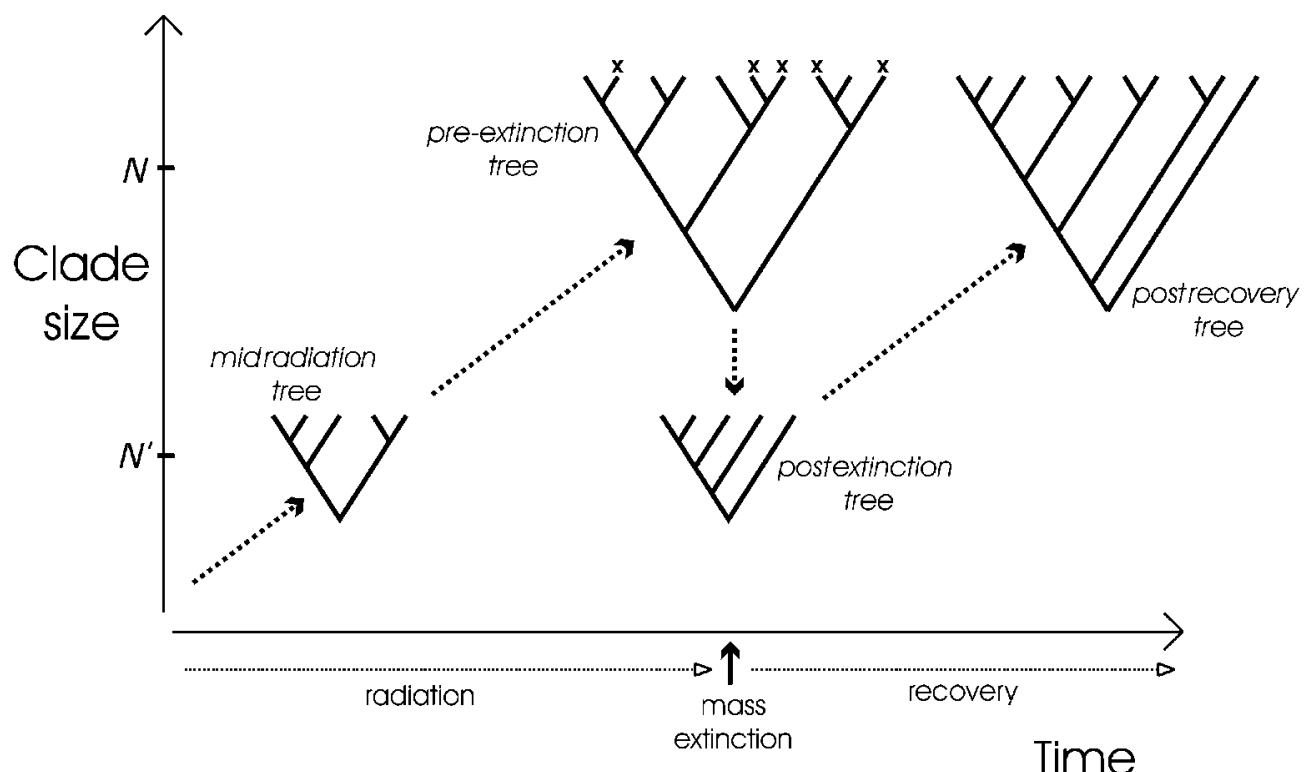

FIGURE 1. A clade diversifying, experiencing random mass extinction, and recovering in diversity. $X$ denotes a lineage removed as part of the mass extinction. Mass extinction is essentially instantaneous, but diversification is gradual. Clade sizes shown are those highlighted in balance and trait-variance comparisons below. 
$N=20$ and $N=80$ were very similar and are not shown). We calculated two quantities for each pre-extinction clade: Colless's imbalance $I_{\mathrm{c}}(0$ for a perfectly balanced tree, 1 for a perfectly imbalanced tree; Heard, 1992) and trait variance $\sigma_{t}^{2}$ (the variance in $\log _{10}$ trait values across the $N$ species at the tips of the tree).

The evolving quantitative trait, $Z$, could represent any trait of individuals (or species) that is associated with speciation rate, such as body size, dispersal ability, generation time, or geographical range (Vrba and Eldredge, 1984; Jablonski, 1987; Heard and Hauser, 1995; Heard, 1996; Purvis, 1996). Evolutionary change in $\mathrm{Z}$ was punctuated and logBrownian (Heard, 1996); change occured only at speciation events (in one of two daughter species), and the logarithm of $\mathrm{Z}$ evolved in a random walk. Therefore, after speciation one daughter species inherited the trait value held by its ancestor, and the other took a new trait value incorporating a stochastic evolutionary change: $\log _{10}\left(Z_{\text {new }}\right)=\log _{10}\left(Z_{\text {old }}\right)+\varepsilon$, where $\varepsilon$ was drawn from a normal distribution with mean 0 and standard deviation $\sigma_{\mathrm{Z}}$. We simulated trait evolution on a logarithmic scale because this made a given proportional change (say, $+10 \%$ ) equally likely for any current trait value.

Speciation rates in our model were controlled by the values of the quantitative trait $Z$. At any time each extant lineage possessed a (relative) speciation rate $s_{i}=Z_{i} / c$, with $c$ a constant chosen such that the probability of multiple speciation events in one iteration was negligible. The time units used, although consistent within and among simulations, were entirely arbitrary. Because we focus on patterns in tree topology rather than on branch lengths, the precise choice of time units is unimportant.

When the underlying quantitative trait does not evolve $\left(\sigma_{Z}=0\right)$, speciation rates are equal across all lineages and through time; i.e., our model simplifies to the well-known equal rates Markov (ERM) model (Yule, 1924; Heard, 1992; Nee, 2001). Larger values of $\sigma_{Z}$ lead to more rapid trait evolution, larger trait variance $\sigma_{t}^{2}$, more speciation-rate heterogeneity, and more imbalanced phylogenetic trees (Heard, 1996). We modeled clades with $\sigma_{Z}=0,0.1$, and 0.2 , a range that produces pre-extinction trees ranging in imbal- ance from the ERM expectation to moderate imbalance. Still larger values $\left(\sigma_{Z} \approx 0.3\right.$, corresponding to at least a twofold change in trait value in $>30 \%$ of speciation events) are required to produce pre-extinction trees with imbalance typical of literature trees (Heard, 1996). We stopped short of including such large values because we were explicitly interested in whether past extinction could contribute to imbalance in real trees, obviating the need to posit such biologically implausible (Heard, 1996) rates of trait evolution.

\section{Phase II: Mass Extinction}

We imposed mass extinctions varying in intensity from $25 \%$ to $90 \%(25 \%, 50 \%, 75 \%$, or $90 \%$; i.e., $N^{\prime}=0.75 N, 0.5 N, 0.25 N$, or $0.1 N$, respectively). We included very severe extinctions because paleontological evidence suggests that such events have occured repeatedly through at Earth history (Raup, 1979; Archibald and Bryant, 1990; Hallam, 1990; Johnson, 1992; Adrain et al., 1998). Extinction was imposed as a single bout, without concurrent speciation events.

We considered three very different extinction regimes: random, selective on diversifiers, and selective on relicts. In a random mass extinction (or "field of bullets" scenario), the species lost were chosen without regard for phylogenetic position, speciation probability, or trait value. In selective mass extinctions, in contrast, extinction probabilities were correlated (positively or negatively) with speciation rates across species. A selective-on-diversifiers extinction had a positive correlation, such that lineages with high speciation rates were most prone to extinction. This regime tended to trim twigs (young species) from the tree. A selectiveon-relicts extinction, in contrast, had a negative correlation and tended to remove long branches (living fossils with no close relatives) from the tree. For simplicity, we modeled selective extinctions that were entirely deterministic; i.e., if $25 \%$ of the species were to be removed in a selective-on-diversifiers extinction, then all (and only) members of the upper quartile of the Z distribution were chosen. Although a model in which extinction risk reflects both trait value and a stochastic component might be more realistic, in previous modeling (Heard and Mooers, 2000) such 
added complications did not greatly affect results.

We implemented each of the three extinction regimes on each pre-extinction tree and calculated imbalance $\left(I_{\mathrm{c}}\right)$ and trait variance $\left(\sigma_{t}^{2}\right)$ for every postextinction tree.

\section{Phase III: Recovery}

Lineages surviving the mass extinction were allowed to resume diversification, following the same trait evolution and speciation model in force before extinction began. The recovery phase continued until the target size $N$ was regained. We calculated imbalance $\left(I_{\mathrm{c}}\right)$ and trait variance $\left(\sigma_{t}^{2}\right)$ for each postrecovery tree.

\section{Analysis}

For each evolutionary scenario (combination of $N, N^{\prime}$, and $\sigma_{Z}$ ), we generated 1,000 pre-extinction clades, each of which was subjected to (and recovered from) each of the three types of mass extinction. For each scenario, we evaluated the effect of mass extinc- tion on tree shape by comparing imbalance and trait variance $\left(I_{\mathrm{c}}\right.$ and $\left.\sigma_{t}^{2}\right)$ between preextinction and postrecovery clades (both of size $N$; Fig. 1 ) and by comparing trait variance between midradiation and postextinction clades (both of size $N^{\prime}$ ). Because trends are so clear, we did not conduct formal statistical analyses, but we show approximate $95 \%$ confidence intervals $(\bar{x} \pm 2 \mathrm{SE})$ in all figures.

\section{RESULTS AND DISCUSSION}

\section{Extinction and Recovery in ERM Trees}

For clades diversifying under the ERM model $\left(\sigma_{Z}=0\right)$, our simulations produced pre-extinction phylogenies with imbalance matching the analytical expectation (Heard, 1992). Random mass extinction (and recovery) does not change imbalance for ERM clades (Fig. 2, left, circles), verifying Slowinski and Guyer's (1989) claim to that effect. Selective extinctions are not defined for ERM clades because they operate only when speciation probability varies among lineages as a result of nonzero trait variance.

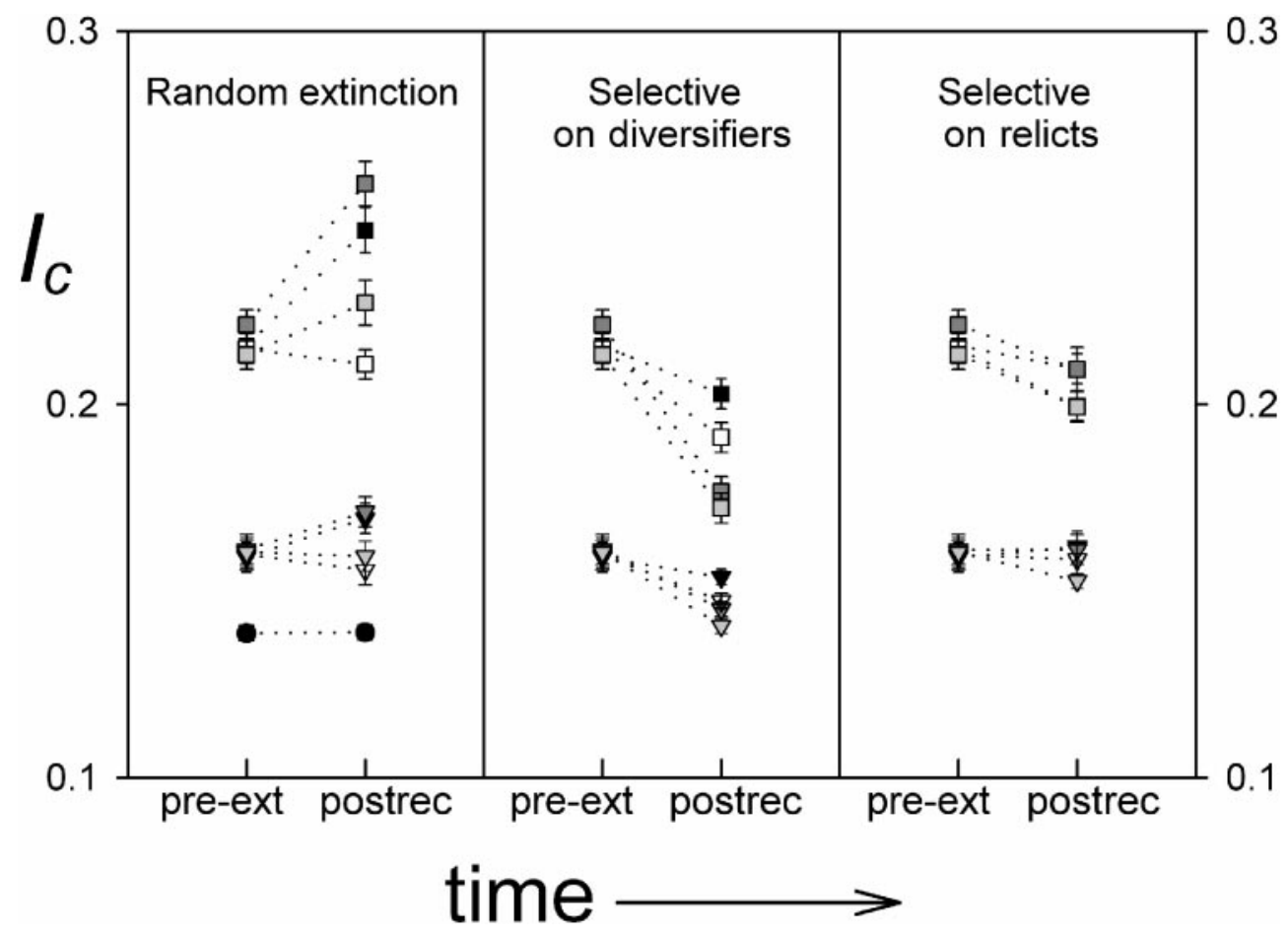

FIGURE 2. Effects of mass extinction and recovery on Colless's imbalance for clades of size 40. Pre-ext $=$ preextinction; postrec $=$ postrecovery. Solid circles indicate ERM clades; triangles indicate $\sigma_{\mathrm{Z}}=0.1$; squares indicate $\sigma_{\mathrm{Z}}=0.2$. Shading represents intensity of extinction: open $=25 \%$; light shading $=50 \%$; dark shading $=75 \%$; solid $=$ $90 \%$. Error bars show \pm 2 SE. 
Random Mass Extinction and Recovery in Non-Markov Trees

For clades diversifying with amonglineage variation in speciation rates $\left(\sigma_{Z}>0\right)$, pre-extinction imbalance increases with $\sigma_{Z}$ as expected (Fig. 2, compare circles, triangles, squares). Also as expected, trait variance increases through diversification (Fig. 3, compare midradiation and pre-extinction trees), and it increases faster for larger $\sigma_{Z}$ (Fig. 3, compare circles, triangles, squares). Trait variance is a critical quantity in our models because it controls the degree of amonglineage variation in speciation rates (Heard, 1996).

In contrast to its lack of effect on ERM clades, random mass extinction in nonERM clades can leave a clear signature: an increase in imbalance in postrecovery trees (compared with the corresponding preextinction trees; Fig. 2, left). The effect is stronger with larger among-lineage variation in speciation rates (larger $\sigma_{Z}$ ). The effect of random mass extinction also varies (nonlinearly) with extinction intensity: it first increases but then peaks and declines as mass extinction becomes more intense. For $\sigma_{Z}=$ 0.2 and $N=40$ (Fig. 2, left, squares), 25\% extinction has a negligible effect on imbalance, $50 \%$ extinction has a moderate effect, and $75 \%$ extinction has a dramatic effect, but $90 \%$ extinction has about the same effect as $75 \%$. Still more severe extinctions actually have little or no effect on imbalance (data not shown).

Random mass extinction affects postrecovery imbalance because although it removes diversity it retains a signal of the evolution that produced that diversity. In particular, trait variance increases during radiation but in most cases is reduced only slightly by random mass extinction (Fig. 3, left; see also Foote, 1997). Therefore, the postextinction clade has much greater $\sigma_{t}^{2}$ than did the midradiation clade of comparable size $\left(N^{\prime}\right)$. Recovery then builds on this greater $\sigma_{t}^{2}$ (and the ensuing among-lineage variation in speciation rates) to produce a postextinction tree that is highly imbalanced.

An exception to the imbalancing effect of random mass extinction arises when extinction is severe enough to reduce the clade

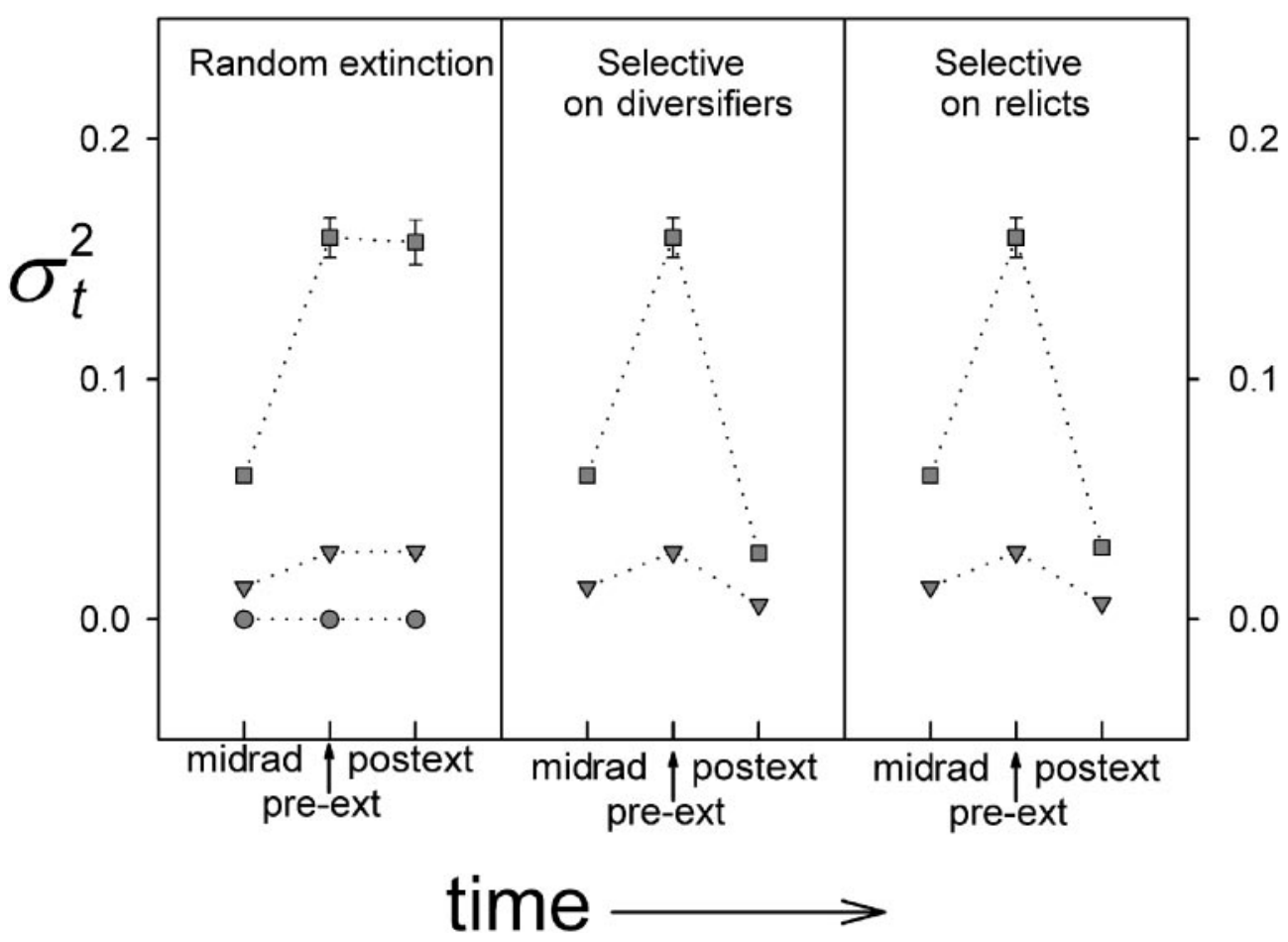

FIGURE 3. Impacts of mass extinction on trait variance $\left(\sigma_{t}^{2}\right)$. All data are for clades of $N=40$ subjected to $75 \%$ extinction $\left(N^{\prime}=10\right)$. Midrad $=$ midradiation; pre-ext $=$ pre-extinction; postrec $=$ postrecovery. Error bars show \pm 2 SE. 
to just a few survivors, in which case postextinction trait variance is reduced sharply. This reduction comes about because random mass extinction is equivalent to taking a random sample from the pre-extinction distribution of trait values. When a small sample is taken from a distribution, the population variance ([sum of squares] $/ n$ ) for the small sample will underestimate the variance of the sampled distribution, a bias corrected by calculating the sample variance as (sum of squares)/(n-1) (see Sokal and Rohlf, 1995). For mass extinctions of moderate severity, the expected reduction in $\sigma_{t}^{2}$ is small, but for our data with $N=40$ this effect is already apparent at $90 \%$ extinction $\left(N^{\prime}=4\right.$; Fig. 2$)$.

\section{Selective Mass Extinction and Recovery}

Mass extinction acting selectively (on the quantitative trait $Z$, which also controls speciation rate) tends to decrease rather than increase imbalance in the postrecovery clades (Fig. 2, center and right), leaving trees closer to the ERM expectation. The explanation is simple: Selective mass extinction sharply reduces $\sigma_{t}^{2}$ by removing species from one extreme of the pre-extinction distribution of trait values (Fig. 3, center and right). The strongly selective extinctions we implemented do not just turn back the clock but instead leave postextinction clades with trait values and speciation probabilities more homogeneous than in the corresponding midradiation clades (Fig. 3, center and right). The effect on postrecovery tree balance can be quite strong for extinctions that are selective on diversifiers (Fig. 2, center) but is weaker for extinctions that are selective on relicts (Fig. 2, right). This contrast arises because selective-on-diversifiers and selectiveon-relicts extinctions have different effects on postextinction tree balance (data not shown). Selective-on-diversifiers extinctions leave extremely balanced postextinction trees (because they remove species from the most diverse lineages), which exacerbates the effects of trait-variance reduction. Selectiveon-relicts extinctions, however, make depauperate lineages even more so, leaving imbalanced postrecovery trees and weakening the effects of trait-variance reduction.

\section{Mass Extinctions in Earth History}

The models explored here illuminate an important contrast between mass extinctions that are selective or random with respect to speciation rates or with respect to heritable traits of individuals or species on which speciation rates depend. Unfortunately, the degree to which mass extinctions through Earth history have been selective in this way remains poorly understood. There is no doubt that at the coarsest scales, mass extinctions have often been selective with respect to taxonomic groups (e.g., between phyla or classes; Raup, 1981; Clemens, 1986; Stanley, 1990), ecological factors (e.g., surface vs. deep waters; Herman, 1990; Thomas, 1990; Canudo et al., 1991; Kaiho, 1992; McGhee, 1995), or regional distributions (e.g., tropical vs. temperate; Stanley, 1984; Raup and Jablonski, 1993 [for rudist but not other bivalves]). At finer scales (e.g., species within families or within local communities), extinction appears to have acted selectively for some lineages in some extinction events (e.g., Keller, 1988; Chatterton and Speyer, 1989; Raup, 1994; Roy, 1996; Smith and Jeffery, 1998; Budd and Johnson, 1999; Eble, 2000) but randomly in many others (e.g., Valentine and Jablonski, 1986; Lupia, 1999; Smith and Bunje, 1999; Eble, 2000). However, in only a handful of cases is there evidence for selectivity with respect to traits known to be, or suspected to be, linked to speciation rate. Several mass extinctions may have had disproportionate effects on marine invertebrates with planktotrophic larvae (Valentine and Jablonski, 1986; Chatterton and Speyer, 1989), and planktotrophic larval stages have been associated with low speciation rates (Heard and Hauser, 1995); therefore, planktotrophy-biased extinctions are selective on relicts. Similarly, lineages with broad geographic ranges often survive mass extinctions well (Jablonski, 1995; Jablonski and Raup, 1995; McKinney, 1995; Erwin, 1998). If such lineages have high speciation rates (because their ranges can be subdivided in many places), then range-biased extinctions are also selective on relicts.

Although theoretical models such as ours cannot say much about selectivity in any specific extinction event, our results are consisent with a scenario in which, through Earth history, mass extinctions have most often been nonselective or only weakly selective with respect to speciation rates. We make this suggestion because the overwhelming empirical pattern is for extant clades to have sharply imbalanced phylogenies. The gap 
between empirical levels of imbalance and predictions from plausible models of speciation processes (Losos and Adler, 1995; Mooers and Heard, 1997; Chan and Moore, 1999 ) is surprisingly broad. Invoking nonrandom extinction would only make the fit to the data poorer, because such mass extinction decreases rather than increases imbalance. Paleontological studies suggest that many past mass extinctions have been nonselective or only weakly selective with respect to many aspects of ecology and morphology (Raup and Boyajian, 1988; Raup, 1994; Foote, 1997; Lupia, 1999; Smith and Bunje, 1999; Eble, 2000). Our simulation results are consistent with a process of diversification that combines heritable variation in speciation rates with episodes of mass extinction largely nonselective with respect to heritable speciation rates. Rather than simply interrupting diversification, mass extinctions may contribute (among other processes) to building the skewed pattern of diversity among clades that is evident in patterns of modern phylogenetic tree balance (Mooers and Heard, 1997).

An interesting goal for future research would be to compare imbalance among clades differing in past extinction history. If past mass extinctions really have contributed to modern-day imbalance, then clades that have suffered severe or repeated extinction episodes should be more imbalanced than those largely or completely spared. Unfortunately, we are currently unable to test this hypothesis directly. Such a test would require large numbers of well-estimated phylogenies for individual clades known to have experienced (or to have been spared) mass extinctions, but only a few such phylogenies (e.g., Harcourt-Brown, 2002) are currently available. Of course, random mass extinctions need not have contributed to imbalance in every modern clade to play an important role in explaining distributions of imbalance scores in compilations of clades (Mooers and Heard, 1997).

The current round of anthropogenic extinctions, although it may rival past mass extinctions in rate and eventually in scope (see Gaston and Spicer, 1998), appears to be acting nonrandomly in that relict species are more vulnerable to human impacts (our selectiveon-relicts regime; Gaston and Blackburn, 1997; McKinney, 1997; Purvis et al., 2000). In this sense, the modern mass extinction may be operating quite differently from mass extinctions in the past. This difference has important consequences not only for the loss of evolutionary history expected (Heard and Mooers, 2000) but also for the taxonomic distribution of diversity (= imbalance) expected among survivors and (in the far and optimistic future) among a postrecovery flora and fauna that may be significantly reshaped by the modern mass extinction.

\section{ACKNOWLEDGMENTS}

We thank Alan de Queiroz, Kate Harcourt-Brown, Paul Pearson, Andy Purvis, and an anonymous reviewer for comments, discussion, and gustatory metaphors. Ed Stam generously shared his unpublished data. S.B.H. thanks Kristie Heard for provoking an important insight. This research was supported by the American (grants DEB 9628969 and DEB 0107752 to S.B.H.), Dutch (PULS grant 831.48.003 to A.Ø.M.), and Canadian (NSERC operating grants to A.Ø.M. and S.B.H.) National Science Foundations.

\section{REFERENCES}

Adrain, J. M., R. A. Fortey, AND S. R. WeStrop. 1998. Post-Cambrian trilobite diversity and evolutionary faunas. Science 280:1922-1925.

ARCHIBALD, J. D., AND L. J. BRYANT. 1990. Differential Cretaceous/Tertiary extinctions of nonmarine vertebrates; evidence from northeastern Montana. Pages 549-562 in Global catastrophes in Earth history; an interdisciplinary conference on impacts, volcanism, and mass mortality, Special Paper 27 (V. L. Sharpton and P. D. Ward, eds.). Geological Society of America, Boulder, Colorado.

BARRACLOUGH, T. G., AND V. SAVOLAINEN. 2001. Evolutionary rates and species diversity in flowering plants. Evolution 55:677-683.

BUDD, A. F., AND K. G. JOHNSON. 1999. Origination preceding extinction during late Cenozoic turnover of Caribbean reefs. Paleobiology 25:188-200.

Canudo, J. I., G. Keller, AND E. Molina. 1991. Cretaceous-Tertiary boundary extinction pattern and faunal turnover at Agost and Caravaca, S.E. Spain. Mar. Micropaleontol. 17:319-342.

CHAN, K. M. A., AND B. R. MOORE. 1999. Accounting for mode of speciation increases power and realism of tests of phylogenetic asymmetry. Am. Nat. 153:332346.

Chatterton, B. D. E., AND S. E. Speyer. 1989. Larval ecology, life history strategies, and patterns of extinction and survivorship among Ordovician trilobites. Paleobiology 15:118-132.

CLEMENS, W. A. 1986. Evolution of the terrestrial vertebrate fauna during the Cretaceous/Tertiary transition. Pages 63-85 in Dynamics of extinction (D. K. Elliot, ed.). Wiley-Interscience, New York.

EBLE, G. J. 2000. Contrasting evolutionary flexibility in sister groups: Disparity and diversity in Mesozoic atelostomate echinoids. Paleobiology 26:56-79. 
ERWIN, D. H. 1998. The end and the beginning: Recoveries from mass extinctions. Trends Ecol. Evol. 13:344349.

FoOTE, M. 1997. The evolution of morphological diversity. Annu. Rev. Ecol. Syst. 28:129-152.

GASTON, K. J., AND T. M. BLACKBURN. 1997. Evolutionary age and risk of extinction in the global avifauna. Evol. Ecol. 11:557-565.

GASTON, K. J., AND J. I. SPICER. 1998. Biodiversity: An introduction. Blackwell Scientific, Oxford, U.K.

Gittleman, J. L., AND A. PuRvis. 1998. Body size and species richness in carnivores and primates. Proc. $R$. Soc. Lond. B 265:113-119.

GRANT, P. R. 1986. Ecology and evolution of Darwin's finches. Princeton University Press, Princeton, New Jersey.

HALlAM, A. 1990. The end-Triassic mass extinction event. Pages 577-580 in Global catastrophes in Earth history; an interdisciplinary conference on impacts, volcanism, and mass mortality, Special Paper 27 (V. L. Sharpton and P. D. Ward, eds.). Geological Society of America, Boulder, Colorado.

HARCOURT-BROWN, K. G. 2002. Tree balance, time slices, and evolutionary turnover in Cretaceous planktonic foraminifera. Syst. Biol. 51:908-916.

Harcourt-Brown, K. G., P. N. Pearson, and M. WILKINSON. 2001. The imbalance of paleontological trees. Paleobiology 27:188-204.

HEARD, S. B. 1992. Patterns in tree balance among cladistic, phenetic, and randomly generated phylogenetic trees. Evolution 46:1818-1826.

HEARD, S. B. 1996. Patterns in phylogenetic tree balance with variable and evolving speciation rates. Evolution 50:2141-2148.

HEARD, S. B., AND D. L. HAUSER. 1995. Key evolutionary innovations and their ecological mechanisms. Hist. Biol. 10:151-173.

Heard, S. B., AND A. Ø. Mooers. 2000. Phylogenetically patterned speciation rates and extinction risks change the loss of evolutionary history during extinctions. Proc. R. Soc. Lond. B 267:613-620.

HERMAN, Y. 1990. Selective extinction of marine plankton in the Paratethys at the end of the Mesozoic Era; a multiple interaction hypothesis. Pages 531-540 in Global catastrophes in Earth history; an interdisciplinary conference on impacts, volcanism, and mass mortality, Special Paper 27 (V. L. Sharpton and P. D. Ward, eds.). Geological Society of America, Boulder, Colorado.

JABLONSKI, D. 1987. Heritability at the species level: Analysis of geographic ranges of Cretaceous mollusks. Science 238:360-363.

JABLONSKI, D. 1995. Extinctions in the fossil record. Pages 25-44 in Extinction rates (J. H. Lawton and R. M. May, eds.). Oxford Univ. Press, New York.

JABLONSKI, D., AND D. M. RAUP. 1995. Selectivity of end-Cretaceous marine bivalve extinctions. Science 268:389-391.

JOHNSON, K. R. 1992. Leaf-fossil evidence for extensive floral extinction at the Cretaceous-Tertiary boundary, North Dakota, USA. Cretaceous Res. 13:91-117.

KAIHO, K. 1992. A low extinction rate of intermediatewater benthic Foraminifera at the Cretaceous-Tertiary boundary. Mar. Micropaleontol. 18:229-259.

KELLER, G. 1988. Extinction, survivorship and evolution of planktic Foraminifera across the Cretaceous/Tertiary boundary at El Kef, Tunisia. Mar. Micropaleontol. 13:239-263.
KIRKPATRICK, M., AND M. SLATKIN. 1993. Searching for evolutionary pattern in the shape of a phylogenetic tree. Evolution 47:1171-1181.

LACK, D. L. 1947. Darwin's finches. Cambridge University Press, Cambridge, U.K.

LIEBERMAN, B. S. 2001. A test of whether rates of speciation were unusually high during the Cambrian radiation. Proc. R. Soc. Lond. B 268:1707-1714.

LOSOS, J. B., AND F. R. ADLER. 1995. Stumped by trees? A generalized null model for patterns of organismal diversity. Am. Nat. 145:329-342.

LUPIA, R. 1999. Discordant morphological disparity and taxonomic diversity during the Cretaceous angiosperm radiation: North American pollen record. Paleobiology 25:1-29.

MCGHEE, G. R., JR. 1995. Geometry of evolution in the biconvex Brachiopoda: Morphological effects of mass extinction. Neues. Jahrb. Geol. Paläontol. Abh B 197:357-382.

MCKINNEY, M. L. 1995. Extinction and selectivity among lower taxa: Gradational patterns and rarefaction error in extinction estimates. Paleobiology 21:300313.

MCKINNEY, M. L. 1997. Extinction vulnerability and selectivity: Combining ecological and paleontological views. Annu. Rev. Ecol. Syst. 28: 495-516.

MOOERS, A. Ø., AND S. B. HEARD. 1997. Inferring evolutionary process from phylogenetic tree shape. Q. Rev. Biol. 72:31-54.

NEE, S. 2001. Inferring speciation rates from phylogenies. Evolution 55:661-668.

NeE, S., T. G. BARRACLOUGH, AND P. H. HARVEY. 1995 Temporal changes in biodiversity: Detecting patterns and identifying causes. Pages 230-252 in Biodiversity: A biology of numbers and difference (K. J. Gaston, ed.). Oxford Univ. Press, Oxford, U.K.

PURVIS, A. 1996. Using interspecies phylogenies to test macroevolutionary hypotheses. Pages 153-168 in New uses for new phylogenies (A. J. Leigh-Brown and J. M. Smith, eds.). Oxford Univ. Press, Oxford, UK.

PURVIS, A., AND P.-M. AgAPOW. 2002. Phylogeny imbalance: Taxonomic level matters. Syst. Biol. 51:844-854

Purvis, A., P.-M. AgAPOW, J. L. GitTleman, AND G. M. MACE. 2000. Nonrandom extinction and the loss of evolutionary history. Science 288:328-330.

RAUP, D. M. 1979. Size of the Permo-Triassic bottleneck and its evolutionary implications. Science 206:217218.

RAUP, D. M. 1981. Extinction: Bad genes or bad luck? Acta Geol. Hisp. 16:25-33.

RAUP, D. M. 1994. The role of extinction in evolution. Proc. Natl. Acad. Sci. USA 91:6758-6763.

RAuP, D. M., AND G. E. BOYAJIAN. 1988. Patterns of generic extinction in the fossil record. Paleobiology 14:109-125.

RAUP, D. M., AND D. JABLONSKI. 1993. Geography of end-Cretaceous marine bivalve extinctions. Science 260:971-973.

RoY, K. 1996. The roles of mass extinction and biotic interaction in large-scale replacements: A reexamination using the fossil record of stromboidean gastropods. Paleobiology 22:436-452.

SlOWINSKI, J. B., AND C. GUYER. 1989. Testing the stochasticity of patterns of organismal diversity: An improved null model. Am. Nat. 134:907-921.

SMITH, A. B., AND C. H. JEFFERY. 1998. Selectivity of extinction among sea urchins at the end of the Cretaceous period. Nature 392:69-71. 
SMITH, L. H., AND P. M. BunJE. 1999. Morphologic diversity of inarticulate brachiopods through the Phanerozoic. Paleobiology 25:396-408.

SOKAL, R. R., AND F. J. ROHLF. 1995. Biometry: The principles and practice of statistics in biological research, 3rd edition. W. H. Freeman, New York.

STAM, E. 2002. Does imbalance in phylogenies reflect only bias? Evolution 56:1292-1295.

STANLEY, S. M. 1984. Marine mass extinctions: A dominant role for temperature. Pages 69-117 in Extinctions (M. H. Nitecki, ed.). Univ. Chicago Press, Chicago.

STANLEY, S. M. 1990. The general correlation between rate of speciation and rate of extinction. Pages 103-127 in Causes of evolution: A paleontological perspective (R. Ross and W. Allmon, eds.). Univ. Chicago Press, Chicago.

THOMAS, E. 1990. Late Cretaceous-early Eocene mass extinctions in the deep sea. Pages 481-495 in Global catastrophes in Earth history; an interdisciplinary con- ference on impacts, volcanism, and mass mortality, Special Paper 27 (V. L. Sharpton and P. D. Ward, eds.). Geological Society of America, Boulder, Colorado.

VALENTINE, J. W., AND D. JABLONSKI. 1986. Mass extinctions: Sensitivity of marine larval types. Proc. Natl. Acad. Sci. USA 83:6912-6914.

VRBA, E. S., AND N. ELDREDGE. 1984. Individuals, hierarchies, and processes: Towards a more complete evolutionary theory. Paleobiology 10:146-171.

WiLLIS, J. C. 1922. Age and area. Cambridge Univ. Press, Cambridge, U.K.

YULE, G. U. 1924. A mathematical theory of evolution, based on the conclusions of Dr. J. C. Willis, F.R.S. Philos. Trans. R. Soc. Lond. B 213:21-87.

First submitted 18 January 2002; revised manuscript returned 13 May 2002; final acceptance 19 August 2002

Associate Editor: Alan de Queiroz 